\title{
OS DILEMAS DO ACESSO ABERTO
}

\section{THE DILEMMA OF OPEN ACCESS}

Recebido em 02.02.2017. Aprovado em 15.05.2017

Avaliado pelo sistema double blind review

DOI: http://dx.doi.org/10.12712/rpca.v11i2.903

\section{Sueli Goulart}

sueli.goulart@ufrgs.br

Universidade Federal do Rio Grande do Sul (UFRGS), Porto Alegre/RS, BRASIL

\section{Rafael Kruter Flores}

rafael.flores@ufrgs.br

Universidade Federal do Rio Grande do Sul (UFRGS), Porto Alegre/RS, BRASIL

\section{Resumo}

O objetivo deste artigo é analisar o processo de transformação de uma tradição cooperativa no campo da produção e disseminação do conhecimento - o projeto SciELO - em interesses de negócios operado por um grande grupo mundial de informação. Ao longo do tempo, SciELO se tornou referência de qualidade e se constituiu em possibilidade efetiva de disputar a hegemonia na divulgação do conhecimento acadêmicocientífico, especialmente da produção latino-americana e caribenha, com o mercado editorial globalizado. Contemplamos uma breve síntese histórica do movimento pelo acesso aberto e do projeto SciELO. Avançamos para o momento atual, quando questões críticas mobilizam os interessados na temática, em especial, a criação do SciELO Citation Index na plataforma Web of Knowledge. Analisamos as questões elencadas sob o prisma do pensamento marxista, particularmente nos aspectos contemporâneos da acumulação do capital, como a crescente privatização dos bens comuns.

Palavras-chave: Acesso aberto. Produção acadêmico-científica. Scielo. Acumulação por espoliação. Periódicos científicos.

\section{Abstract}

The objective of this paper is to analyze the process of conversion of a cooperative tradition in the field of production and dissemination of knowledge - the SciELO project - in target business operated by a big player in the information sector. Over time, SciELO has become a quality reference and an effective possibility to contest the hegemony in the dissemination of academic and scientific knowledge, especially for the Latin American and Caribbean production, with the global publishing market. We offer a historical overview of the open access movement and the SciELO project. We then analyze the contemporary moment, when critical issues mobilize those interested in the subject, in particular the creation of the SciELO Citation Index in Web of Knowledge platform. We analyze the listed issues through the prism of Marxist thought, particularly in the contemporary aspects of capital accumulation as the increasing privatization of common goods.

Keywords: Open access. Scientific-academic production. Scielo. Accumulation by dispossession. Scientific journals. 


\section{Introdução}

O objetivo deste artigo é analisar o processo de transformação de uma experiência cooperativa no campo da organização e disseminação do conhecimento - o projeto SciELO - em alvo de interesses de negócios operado por um grande grupo mundial de informação. Para isso, apresentamos as contradições em torno do tema do acesso aberto a publicações acadêmicocientíficas, ilustradas pela trajetória do projeto SciELO e suas conexões com o circuito da comunicação científica. Incluem-se os processos de produção de conhecimento acadêmico-científico, os mecanismos de disseminação e acesso e de avaliação de pesquisadores e instituições. Passados mais de 15 anos da experiência pioneira e bem-sucedida do projeto SciELO, os atores envolvidos veem-se diante de desafios que exigem reflexão e posicionamento. Criado em 1998, por iniciativa do Centro Latino-Americano e do Caribe de Informações em Ciências da Saúde (BIREME) em parceria com a Fundação de Amparo à Pesquisa do Estado de São Paulo (FAPESP) e editores de periódicos científicos, o projeto SciELO conta com aproximadamente 950 revistas em sua coleção, todas franqueadas ao acesso aberto, via licenciamento Creative Commons.

Essa iniciativa não se restringe a publicar textos, livros ou periódicos. SciELO é uma biblioteca virtual de revistas científicas eletrônicas, predominantemente latino-americanas. Sobre a coleção incorporada são produzidos indicadores de uso e impacto dos artigos ali publicados. Desde seu início, SciELO adotou metodologia capaz de garantir padrões de indexação e recuperação de informações de alta qualidade o que, no universo caótico da Internet e da comunicação científica, é um recurso essencial. Nesse setor, tais recursos implicam não apenas na possibilidade de recuperar informações mas também de oferecer instrumentos de avaliação da produtividade de pesquisadores e instituições. Com rigorosos critérios de seleção, SciELO também contribuiu para a melhoria dos periódicos científicos, particularmente no que se refere a regularização de periodicidade, editoração, mecanismos de avaliação de artigos etc. Ao longo do tempo, tornou-se uma referência de qualidade, isto é, integrar a coleção SciELO é um indicativo relevante para as revistas científicas nacionais. Por isso e por outras razões, detalhadas ao longo deste artigo, SciELO constituiu-se em uma possibilidade efetiva de disputar a hegemonia na divulgação do conhecimento acadêmicocientífico latino-americano e caribenho em um mercado editorial globalizado.
A experiência do projeto SciELO, sua trajetória, o estágio atual bem como as perspectivas futuras se apresentam com um potencial significativo para a ilustração das contradições nesse setor. As contradições estão vinculadas às práticas de produção e disseminação do conhecimento acadêmico científico, em vista de suas especificidades, dentre as quais, o caráter ontologicamente compartilhado e coletivo de sua produção e os processos social e politicamente construídos para sua certificação e legitimidade.

Ademais, como afirma Lefebvre (2014, p. 621, tradução nossa), "o conhecimento é um processo acumulativo", logo, pressupõe uma forma e é parte das condições de outro processo: a acumulação de capital. Desse modo, as especificidades do processo de produção de conhecimento são permanentemente confrontadas com as necessidades da acumulação de capital. Por isso, nossa análise está inspirada na compreensão de Marx (1990), segundo a qual o trabalho humano, no sistema capitalista, deve necessariamente ser convertido em mercadoria. Essa dinâmica não élinear enem automática, envolvendo contradições, conflitos, avanços e recuos. Este artigo busca apresentar alguns desses aspectos no processo de criação e nos desdobramentos do SciELO.

A compreensão dialética do que observamos e a reflexão que propomos visa contribuir para ampliara compreensão dos desafios e dos rumos para sua superação, valorizando as possibilidades que a tradição brasileira na construção de serviços cooperativos de informação e os avanços tecnológicos permitem. Como afirma Diniz (2015, p. 479), em editorial publicado em Revista de Administração de Empresas, este é um tema a ser explorado pelos pesquisadores em Administração, com vistas a "entender melhor os modelos de acesso aberto em periódicos científicos". Com esse propósito, iniciamos com uma breve síntese histórica do movimento pelo acesso aberto e do projeto SciELO. Avançaremos para o momento atual, quando questões críticas mobilizam os interessados na temática: o polêmico e provocativo artigo publicado na revista Science (BOHANNON, 2013), colocando em xeque o processo de avaliação por pares em periódicos de acesso aberto da modalidade dourada (que cobram taxas para publicação); a discussão na comunidade científicoacadêmica brasileira sobre os periódicos predatórios, incluídos no Qualis; a internacionalização dos periódicos brasileiros; e, em especial, a criação do SciELO Citation Index na plataforma $W e b$ of Knowledge, de propriedade da Thomson Reuters. Analisaremos as questões elencadas sob o prisma do pensamento marxista, particularmente nos aspectos contemporâneos da acumulação, incluída a 
espoliação de bens comuns tal como é o conhecimento. Finalizamos com reflexões acerca das razões e estratégias na apropriação desses bens.

\section{A indústria do periódico científico, o movimento pelo acesso aberto e o projeto Scielo}

No eixo da discussão que propomos estão os periódicos científicos. Criados em 1665 para publicar notícias sobre atividades científicas, tornaram-se uma instituição social ao cumprirem, na modernidade, ao menos três funções centrais (HERSCHMAN, 1970). Como suportes físicos de registros de estudos científicos, os periódicos materializaram a formação de um amplo arquivo do conhecimento produzido, qualificados por um iniciante sistema de arbitragem (editor-referee system) e passaram a influir nas motivações para a ciência (MERTON, 1973). Como um meio de comunicação que disseminava o conhecimento produzido, os periódicos permitiram a interação entre pesquisadores, estimulando diálogos, comentários e, em articulação com a função de registro, possibilitavam a recuperação de informações registradas, via consulta a sumários. Esta funcionalidade foi determinante para a criação dos serviços de recuperação, ou, dos então chamados periódicos secundários (HERSCHMAN, 1970), que reuniam, inicialmente, um conjunto de abstracts de diversas publicações primárias, em áreas temáticas específicas. Por fim e, como sói acontecer em processos de institucionalização, os periódicos alcançavam e transmitiam prestígio e reconhecimento entre cientistas e programas de formação. Herschman (1970, p. 38) chamava a atenção sobre as implicações do "publish or perish": se era verdade que as publicações permitiam o controle sobre a produtividade de programas e pesquisadores, também era verdadeiro o interesse pelo reconhecimento que transmitiam. Alçadas ao patamar de instituição social, as publicações científicas se consolidaram como um dos mais importantes acervos de conhecimento acadêmico-científico da humanidade uma vez que, do ponto-de-vista funcional, garantiam a propriedade de ideias, registradas sob autoria, ao mesmo tempo que as tornavam públicas. O prestígio e o reconhecimento vinculados a certas publicações alcançavam também editores, avaliadores e, por via de consequência, os assinantes, institucionalizando o fluxo da comunicação científica como constituinte de critérios de cientificidade e avaliação da produção científica.
Ao longo do tempo, e particularmente após a Segunda Guerra Mundial, o conhecimento científico passou a despertar fortes interesses mercantis por sua apropriação ao setor produtivo, mas também em razão da necessidade de organizar o seu acesso. O crescimento exponencial no número de publicações (as fontes primárias) passam a demandar a criação de publicações secundárias, aquelas que reúnem abstracts de diversas periódicos, para facilitação do acesso a áreas e temas específicos. Começam a ser criados os serviços de registro, armazenamento, recuperação da informação, acesso à literatura publicada e de comunicação formal ou informal entre pesquisadores, abrindo espaço para o fortalecimento da indústria editorial.

Em 1955, Eugene Garfield percebeu a importância de capturar e organizar conhecimentos oriundos de pesquisas para facilitar novas descobertas (THOMSON REUTERS, 2013). Naquele mesmo ano, propôs, em artigo publicado na revista Science, a criação de um sistema bibliográfico para apoiar a seleção de periódicos relevantes para bibliotecas e pesquisadores, de modo a mapear o conhecimento produzido em áreas específicas, em determinado período de tempo. Foi também a primeira vez em que expôs a ideia da criação de um fator de impacto para medir citações de periódicos e de autores (GARFIELD, 1955). Na década de 1960, Garfield criou o Science Citation Index (SCI), no âmbito do Institute for Scientific Information (ISI), de sua propriedade, para quantificar citações bibliográficas de artigos de periódicos em áreas específicas. Archambaut e Larivière (2009) lembram que, embora a ideia de medição do impacto de periódicos tenha surgido ainda em 1927 para apoiar a seleção de material para as bibliotecas estadunidenses, sua utilização em grande escala se efetivou com a criação do SCI, que possibilitou a criação do Journal of Citation Report (JCR), do mesmo ISI. Como indicam os mesmos autores, sob o efeito de uma profecia auto-realizadora, periódicos que apresentam maior FI são mais procurados por autores para publicação e para leitura, fechando um círculo, cujo resultado é a sobrevalorização da coleção indexada no SCI, com evidentes repercussões sobre os custos de assinaturas de títulos ali incluídos. A dimensão do potencial econômico destes serviços pode ser inferida pelas mudanças em sua propriedade: em 1992 o ISI foi adquirido pela Thomson Corporation que, desde 2008 fundiu-se à agência Reuters, tornando-se a maior empresa de informação do mundo.

Dados de 123 bibliotecas vinculadas Association of Research Libraries, dos EUA mostram que entre 1986 
e 2004, os custos com a aquisição de periódicos subiram $273 \%$. O gasto médio dessas bibliotecas com assinaturas, nos anos de 2003 e 2004 foi superior a 5,5 milhões de dólares (BRIQUET DE LEMOS, 2005). Relatório da House of Commons (UNITED KINGDOM, 2004) identificou que o lucro dos editores de revistas científicas é significativamente mais alto do que dos demais setores editoriais. O lucro operacional da Reed Elsevier, por exemplo, citada como líder do mercado à época, foi em torno de 34\%. O mesmo Relatório informava que apenas oito grandes grupos editores concentram cerca de $70 \%$ dos títulos, incluindose as áreas de ciências, tecnologia e saúde. Em uma cronologia de fusões e aquisições, Briquet de Lemos (2005, p.2) aponta a tendência "ao monopólio e à cartelização" nesse setor, fato que certamente guarda relação com o aumento dos preços de assinaturas. Ao analisarem 45 milhões de documentos indexados no Web of Science, no período de 1973 a 2013, Larivière, Haustein e Mongeon (2015) concluíram que mais de $50 \%$ dos artigos publicados estavam nas mãos dos quatro maiores players do cenário: Reed-Elsevier, Wiley-Blackwell, Springer e Taylor\&Francis. Resta ainda acrescentar que as assinaturas são quase que exclusivamente adquiridas por instituições de pesquisas, universidades e bibliotecas, fator também bastante favorável a uma supervalorização nas assinaturas institucionais.

Somam-se a estes fatores que as novas tecnologias de informação e comunicação fortemente desenvolvidas a partir dos anos 90 do século passado, tornaram evidentes as possibilidades de mudança nesse quadro. $\mathrm{Da}$ criação dos primeiros repositórios digitais à Convenção de Santa Fé sobre Open Archives Iniciative (OAI), chegou-se rapidamente aos pacotes de software desenvolvidos sob a orientação de livre acesso e uso, como o Open Journal Systems (OJS), implementado pelo Public Knowledge Project (PKP). Seguiram-se diversas declarações de sociedades comunitárias ou científicas em apoio ao acesso aberto, dentre as quais, a de Budapeste - Budapest Open Access Initiative (BOAI), patrocinada pelo Open Society Institute, em 2001 e a de Bethesda - Bethesda Statement on Open Access Publishing, resultante da reunião de cientistas, editores e bibliotecários vinculados à área biomédica, em 2003. No Brasil são praticamente simultâneas as declarações do Instituto Brasileiro de Informação Científica e Tecnológica (IBICT), vinculado ao Ministério da Ciência e Tecnologia e a da BIREME (GOULART, 2006). Ambas as declarações são de 2005 e, tanto o IBICT como a BIREME, tornaram-se atores determinantes para a ampliação do número e da legitimidade que os periódicos eletrônicos de acesso aberto tiveram no País. No caso do IBICT, sua equipe de técnicos traduziu e customizou, em 2003, o OJS, disponibilizando a versão oficial, em português, com a denominação de Sistema de Editoração Eletrônica de Revistas (SEER), largamente utilizado por diferentes áreas e instituições brasileiras. A BIREME liderou a criação do projeto SciELO, em parceria com a FAPESP e editores de revistas científicas brasileiras.

A descrição dos propósitos que orientaram a criação e o desenvolvimento do SciELO bem como as repercussões sobre a produção e a disseminação do conhecimento para pesquisadores e instituições da região é elemento importante para a reflexão que propomos. Segundo Packer e outros, (1998, p. 109), o interesse da FAPESP era de "aumentar a visibilidade da produção científica nacional e criar mecanismos de avaliação complementares aos do Institute for Scientific Information". Para a BIREME interessava desenvolver uma metodologia para "publicação eletrônica, cuja aplicação pudesse complementar a metodologia de registro bibliográfico e indexação utilizada na produção descentralizada da base de dados bibliográficos Literatura Latino-Americana e do Caribe em Ciências da Saúde (LILACS)". Cerca de dez editores de revistas científicas nacionais aprovaram e aderiram ao projeto piloto, apostando nas novas possibilidades para a disseminação do conhecimento produzido local e regionalmente. Compromisso com a pesquisa e com o aprendizado conjunto em busca de uma solução que atendesse aos interesses de todos eram os princípios orientadores da parceria estabelecida

Dentre as justificativas e oportunidades para a criação do SciELO estavam o aprimoramento do controle bibliográfico, da visibilidade e da avaliação da literatura científica produzida nas regiões da América Latina e Caribe e a relação custo-beneficio da publicação eletrônica frente à publicação em papel. Preocupados com a condição a que estão expostos instituições, pesquisadores e serviços informacionais nos países periféricos, afirmavam também a necessidade de que as soluções para SciELO se baseassem "em tecnologias de informação baratas, preferencialmente de domínio público, de fácil operação e transferíveis para diferentes plataformas de equipamentos". Tomado como princípio, essa condição contribuiria para "dotar a Metodologia SciELO de abertura tecnológica e de independência das soluções caras, características necessárias para responder às condições 
de desenvolvimento econômico e tecnológico da região". Do mesmo modo, a implementação da Metodologia em módulos que abrangessem todo o processo de publicação eletrônica, a partir de artigos em formato digital, enfatizava seu "caráter aberto" (PACKER e outros, 1998, p. 113).

As possibilidades da publicação eletrônica apontavam para múltiplas perspectivas e tanto se afirmavam pela contribuição que aportariam ao processo tradicional da comunicação científica como também pela renovação e mudança no modelo dominante. Entre as últimas, estariam a possibilidade de publicação direta de artigos pelos próprios autores na Internet e "a criação e operação de bases de dados de artigos produzidos por comunidades de autores, por exemplo, as formadas por cientistas de uma universidade ou instituto de pesquisa, membros de sociedades científicas e outros" (PACKER e outros, 1998, p. 110-111). Esta foi a possibilidade explicitamente explorada por SciELO, mediante a reprodução da base cooperativa proporcionada pela experiência da BIREME, somada aos propósitos da FAPESP e dos editores científicos, em sua maioria vinculados a universidades, instituições de pesquisa ou comunidades científicas.

Entretanto, desde 1998, o grupo de formuladores do SciELO antevia alguns aspectos polêmicos como:

a diminuição do papel das editoras científicas com fins lucrativos, a redefinição do direito de autor, a substituição do processo clássico de avaliação por pares por uma revisão pública e interativa, a eliminação da organização dos periódicos em volumes e números em favor da publicação de artigos individuais e, por último, a eliminação da própria identidade dos periódicos científicos em benefício das bases de dados de artigos [...]. Entretanto, embora exista um número crescente de iniciativas para a renovação do modelo de comunicação científica, a tendência dominante na comunidade de editores e publicadores científicos é manter a sua essência e aperfeiçoar progressivamente $\mathrm{O}$ seu funcionamento por meio de contribuições das tecnologias de informação. (PACKER e outros, 1998, p. 110-111)
Manifestavam também preocupação com o desenvolvimento de um modelo econômico apropriado aos objetivos do SciELO e às necessidades de financiamento para a produção dos periódicos participantes. Previam que

em um primeiro momento,
a publicação gratuita dos
periódicos na Internet
facilitará a sua disseminação
e acessibilidade, mas exigirá
mecanismos complementares de
financiamento para as revistas. Os
recursos financeiros poderão ser
mobilizados a partir da combinação
de diferentes fontes, como as
agências de apoio a pesquisas,
as organizações responsáveis
pelas revistas, o patrocínio de
empresas privadas etc. Poderá
ocorrer também uma combinação
de recursos com uma política de
preços baixos. Por último, a busca
de uma operação progressivamente
auto-sustentada. A definição desse
modelo econômico representa um
dos grandes desafios futuros para
o projeto e sua formulação deverá
contar com o aporte de todos os
seus agentes. (PACKER e outros,
1998 , p. 120)

O Projeto nascia permeado por paradoxos: buscava se afirmar como iniciativa apropriada ao contexto latinoamericano e caribenho, mas sem perder a referência a padrões internacionais, especificamente a imperiosa necessidade de produzir indicadores de citação. Explicitamente, seus formuladores perguntavam: "a região [América Latina e Caribe] requer indicadores próprios à ciência local, ou são suficientes os indicadores consagrados nos países desenvolvidos, mais particularmente os produzidos pelo ISI?" (PACKER e outros, 1998, p. 120)

As respostas apresentadas nos últimos anos são emblemáticas, tanto pela coerência das proposições e preocupações que estavam na origem do movimento pelo acesso aberto e do Projeto SciELO, como pelos rumos que tomaram, no contexto de aprofundamento de crise do capitalismo. Os elementos apresentados a seguir situam a discussão. 


\section{0 acesso aberto como modelo lucrativo de negócio}

Estudo feito para a Comissão Européia mostrou que cerca de 50\% dos artigos publicados entre 2004 e 2011 nos países da Comunidade Europeia, Estados Unidos, Canadá, Japão e Brasil encontram-se disponíveis em acesso aberto na Internet. O Brasil lidera com 63\% dos artigos em acesso aberto em grande parte devido ao SciELO (QUANTO... 2013).

Os efeitos desses números foram rapidamente captados pelo mercado editorial. Informações coletadas pelo BioMed Central (2005) já indicavam, por exemplo, que periódicos de acesso aberto alcançavam índices de citação similares aos que exigiam pagamento para subscrição. Também em 2005, a Association of Learned and Professional Society Publishers (ALPSP), publicou relatório sobre os impactos financeiros e não financeiros de modelos alternativos de negócios em periódicos acadêmico-científicos. A ALPSP (2005) argumentava que a interferência das iniciativas em acesso aberto era fundamentalmente retórica e que não afetava a situação vigente, de manutenção de um mercado cativo, no qual ela é um ator dominante. Suas estratégias para a manutenção do status quo já incluíam inclusive a adoção da ideia de acesso aberto.

Para Solomon (2013, p. 25), as primeiras reações às iniciativas de acesso aberto foram fortes: "os editores comerciais que lucravam muito com as publicações científicas e investiam pesado em novas plataformas digitais ficaram obviamente horrorizados, mas eles não estavam sozinhos". O autor chama a atenção para o fato de que também algumas sociedades científicas que no passado lutaram para ter suas publicações, estavam já acostumadas a lucrar com seus periódicos. Muito rapidamente o acesso aberto passou a ser visto no cenário internacional como modelo de negócio bastante promissor, atraindo a atenção de grandes editores privados, como Sage e Elsevier, por exemplo (QUANTO... 2013). Com efeito, é crescente o número de editores privados que disponibilizam artigos em acesso aberto, mas cobram por artigo publicado. Os preços para publicação de artigos têm variado entre US\$ 1350,00 a US $\$ 5000$ para publicações submetidas à revisão por pares, especialmente quando bem posicionadas no ranking de citações, ou, com elevado fator de impacto.

Sob condições de pagamento para publicação, de um lado, surgem polêmicas quanto aos critérios de avaliação de artigos em periódicos de acesso aberto, na modalidade dourada, como a exposta por Bohannon, (2013). De outro lado, sociedades científicas e pesquisadores renomados clamam pelo fim do uso do fator de impacto (FI) como medida de avaliação da pesquisa. Este foi o caso da American Society for Cell Biology que publicou, em 2012, a San Francisco Declaration on Research Assessment (DORA). Essa declaração recomenda que o FI não seja mais utilizado em avaliações relativas a financiamento, promoções na carreira e contratações de acadêmicos. Para os signatários de DORA,

o uso isolado do FI na avaliação acadêmica é altamente destrutivo, [...] pois pode impedir periódicos de publicar artigos de áreas ou assuntos menos citados, além de sobrecarregar periódicos de alto impacto com submissões muitas vezes inadequadas. Porém, a consequência mais nefasta para a ciência é impedir o progresso natural da pesquisa, que, na busca por novas abordagens, pode levar a períodos relativamente longos sem gerar publicações. Os pesquisadores devem poder 'usufruir' deste período sem publicações e citações sem ser penalizados por isso. (DECLARAÇÃO..., 2013)

Em dezembro de 2013, um dos ganhadores do prêmio Nobel, Dr. Randy Schekman, criticou a maneira pela qual as revistas científicas estão se desenvolvendo. Ele faz duas acusações contra o que chama de "revistas de luxo" (WHAT'S WRONG..., 2013, tradução nossa). A primeira é de que elas restringem artificialmente o número de artigos aceitos - agindo como designers de moda que criam bolsas ou roupas de edição limitada, seguindo a lógica de que a escassez alimenta a demanda. Esse comportamento, diz ele, é mais propício para a venda de assinaturas do que para a publicação da melhor pesquisa. Em segundo lugar, argumenta que a ciência como um todo está sendo distorcida por incentivos perversos, especialmente a tirania do IF. Os pesquisadores que publicam em periódicos com alto fator de impacto como Cell, Nature e Science podem esperar promoção, aumentos salariais e elogios profissionais. Os demais, permanecem na obscuridade (WHAT’S WRONG..., 2013). No Brasil 
acrecentaríamos: e sumariamente desligados dos Programas de Pós-Graduação.

Que o conhecimento acadêmico-científico, no sistema capitalista, é uma mercadoria de forte apelo comercial não há dúvidas. Mas, o óbvio, tomado como natural, ou, imune a questionamentos, esconde mecanismos intrincados e paradoxais que, desvelados, expõem a nu o alto grau de contradições que o constitui. No caso da indústria editorial já se ultrapassou o fato concreto do valor econômico do conhecimento acadêmicocientífico porque capaz de gerar produtos, inovações, ou, melhorias das condições de vida das populações. Matizado com critérios de avaliação de produtividade $\mathrm{e}$ de rankings de excelência de pesquisadores e instituições, num cenário de competição e de crise do capitalismo, já não é somente o conhecimento que conta. É sua forma mercadoria - a publicação. E é em torno desta mercadoria que grandes interesses empresariais se mobilizam. Nesse empreendimento, contam com a crescente funcionalização das universidades e das agências financiadoras de pesquisa aos interesses do capital por meio, por exemplo, da obsessão por produtividade, medida por indicadores de citação, ou seja, o consagrado fator de impacto, concebido por Eugene Garfield, em 1955, quando iniciou a publicação do Science Citation Index (SCI).

Desde a década de 1990 o fator de impacto de periódicos (e de artigos) é a matéria prima do Journal Citation Reports (JCR), parte integrante do Web of Science, atualmente de propriedade da Thomson Reuters. De ícone dos critérios de avaliação de periódicos a elemento determinante da qualidade do conhecimento produzido por pesquisadores, instituições e países foi um passo. Ao nosso ver, decisivo na supervalorização de publicações de artigos em veículos com alto fator de impacto, ou seja, aqueles que estão relacionados no JCR. Sendo a principal fonte legitimada pela comunidade acadêmico-científica internacional no estabelecimento de parâmetros para classificação de autores e periódicos, o JCR potencializou a Thomson Reuters como um dos mais importantes players no mercado editorial da ciência.

Apresentam-se, então, os paradoxos mais evidentes, particularmente para os países periféricos, como o Brasil. Como afirmava Muller (2006, p. 33) em meados da primeira década do nosso século,

Aqui, [...] é o Estado que financia a educação dos novos cientistas, desde seu início até a obtenção dos graus mais altos, seja em instituição nacional ou estrangeira. Uma vez formado e já pesquisando, normalmente em uma universidade também mantida pelo Estado, sua pesquisa é frequentemente financiada pelas agências de fomento federais ou estaduais, vale dizer, de novo dinheiro público. Terminada a pesquisa, sua divulgação em reuniões e congressos será de novo financiada pelo Estado. Finalmente, a publicação em revista indexada poderá também receber auxílios dos cofres públicos, pois em algumas áreas as editoras cobram dos autores por página publicada. Ao publicar em uma revista, é hábito o autor ceder às editoras o direito autoral sobre o artigo. Uma vez publicada, entra em cena de novo o Estado, financiando as bibliotecas para sua compra.

Dados apresentados pelo então presidente da CAPES, mostraram que em 2004 foram despendidos 22 milhões de dólares para garantir o acesso a um total de 8.516 títulos de periódicos nacionais e internacionais, reunidos no Portal de Periódicos. Em 2013 os gastos alcançaram 94 milhões de dólares para um total de 35.070 títulos. Os investimentos tiveram um aumento de $327 \%$, enquanto o número de títulos aumentou 312\% (GUIMARÃES, 2014).

Acrescente-se que a pressão por produtividade e a obsessão pelo fator de impacto como critério de avaliação, especialmente para a pós-graduação, faz com que pesquisadores e instituições dirijam suas publicações para os periódicos mais prestigiosos, sempre com base no tal fator de impacto, movendo um círculo vicioso perverso. Apropriação privada de bem público, visto serem privados os grandes players da comunicação científica; e públicos os recursos que possibilitam a produção. Em outras palavras, instituições e pesquisadores produzem, inclusive por mecanismos de indução das agências públicas de fomento a pesquisa "matéria-prima abundante, inesgotável e, antes de tudo, fornecida gratuitamente e sem expectativa de recompensa material" (BRIQUET DE LEMOS, 2005). Nada que nossa longa trajetória colonial não consiga explicar, em uma forma de 
acumulação primitiva no campo da produção do conhecimento, ou, para atualizar com as palavras de Harvey (2010) - acumulação por espoliação.

No eixo das pressões que hoje confrontam as iniciativas de acesso aberto está uma concepção de avaliação e legitimação do conhecimento científicoacadêmico funcional aos interesses do capitalismo que, em momentos de crise como o atual, avança para todo e qualquer espaço. A publicação dos resultados de pesquisa, concebida ela própria como mercadoria, guarda relação com os modos mediante os quais a universidade tornou-se alvo dos interesses do capital e de como agências governamentais, como a CAPES, ou a FAPESP, por exemplo, "se tornaram mediadores e porta-vozes desses interesses, traduzindo-os em demandas e transmitindo-as às universidades [...]" (MACHADO e BIANCHETTI, 2011).

Não por acaso o aprofundamento dessa situação se dá a partir da década de 1990, a mesma do alastramento da ideologia neoliberal para todas as instâncias. Também não pode ser atribuído ao acaso que, após 15 anos de efetivo trabalho cooperativo, o Projeto SciELO passe a integrar o portfólio de serviços de um dos maiores conglomerados de informação do mundo. Em entrevista, Packer (2013) afirmou que este fato não altera a condição de acesso aberto às publicações do SciELO. Não obstante, há uma clara transferência de valor para a Thomson Reuters, uma vez que a incorporação de SciELO Citation Index, produto de trabalho coletivo e cooperativo de diversas instituições, passa a compor pacotes informacionais, vendidos a preços significativos às mesmas instituições que, via de regra, financiam a produção dessa matéria-prima.

Esse acontecimento, celebrado por alguns como a medida do sucesso alcançado pelo Projeto, soa como capitulação para outros. A contraditória interpretação tem, como base, a contradição sugerida na introdução deste texto - o conhecimento como bem comum e como mercadoria. O fato de se ter inaugurado uma nova forma de organização e acesso ao conhecimento acadêmico-científico não encerra a discussão num jogo de vitórias e capitulações. Para além dos recursos tecnológicos que viabilizam as iniciativas de acesso aberto, é necessário refletir sobre a natureza política de que se revestem. Ou seja, é necessário disputar a concepção sobre a natureza da matéria-prima.

Essa reflexão aparece mais frequentemente em relação ao tema das patentes, quando conhecimentos (acadêmicos, científicos ou tradicionais) são apropriados privadamente, como se pode ver no setor farmacêutico, por exemplo, com consequências por vezes fatais a parcelas significativas da população dos países periféricos. Em 2000, Philippe Quéau chamava a atenção para "a criação de novos direitos de propriedade intelectual [...] o assim chamado direito sui generis, que protege a atividade, não inventiva, de constituição de bases de dados a partir de elementos pré-existentes". E exemplificava:

Em 1985, todos os dados do programa público americano de observação da Terra por satélite Landsat foram concedidos à EOPSat, uma associada da General Motors e da General Electric. Resultado: o acesso aos dados ficou vinte vezes mais caro. As instituições universitárias não podiam mais conseguir essas informações custosas que, no entanto, foram obtidas graças a um financiamento inteiramente público. Sua exploração favoreceu sobretudo as grandes companhias petrolíferas, que assim receberam um subsídio direto. (QUÉAU, 2000)

A analogia com o que pode vir a ocorrer com SciELO é preocupante. Em um de seus últimos textos, Daniel Bensaid (2010) fazia uma análise da atualidade do Manifesto Comunista e afirmava que "sob o reino do capital, todo progresso aparente tem sua contrapartida de regressão e de destruição. Em última instância, não consiste em mais do que mudar a forma de servidão" (BENSAID, 2010). Veja-se que o avanço tecnológico permitiu a proposição mais democrática do acesso aberto, como mostra por exemplo o estudo de Acharya e outros (2014). Os autores analisaram artigos publicados entre 1995-2013 e elegeram os dez periódicos mais citados (que os autores chamaram de elite) e os 1000 artigos mais citados em cada ano. Como conclusão, identificaram uma crescente migração dos artigos mais citados, que paulatinamente foram deixando de figurar nos periódicos elite e passaram a figurar cada vez mais nos periódicos 'não-elite'. Temos aí uma aparente democratização do acesso possibilitado pela tecnologia, mas uma análise da gênese, dos mecanismos estruturais e das formas de propriedade revela que tal democratização 
(que efetivamente ocorre) tem como contrapartida a concentração de capital.

Uma das primeiras medidas tomadas sob as diretrizes da internacionalização, profissionalização e sustentabilidade financeira e, pode-se afirmar, para o alinhamento necessário à inclusão do SciELO Citation Index no Web of Knowledge, foi a mudança nos critérios para a inclusão de periódicos brasileiros na coleção (SCIELO, 2014). Uma breve leitura dos novos critérios indica o conteúdo de tais diretrizes. Para a internacionalização, exigem-se percentuais mínimos de editores associados e pareceristas estrangeiros (20\% e 25\% respectivamente); de artigos no idioma inglês $(60 \%)$, e de autores (20\%). Para avançar na profissionalização na gestão dos periódicos, a exigência de que, até o final de 2015, os periódicos operem com um sistema online de gestão de manuscritos; Scielo opera com o ScholarOne, da Thomson Reuters e, juntamente com esta corporação, oferece treinamentos aos gestores de revistas integrantes da coleção (MENDONÇA, 2015). Embora não hajam prescrições para a sustentabilidade financeira, exige-se que os periódicos mantenham, a partir julho de 2015, um plano de marketing e divulgação. Percebe-se, assim, que a sustentabilidade financeira parece ser muito mais uma exigência da FAPESP para o Programa Scielo do que uma preocupação com a capacidade que terão os editores, as sociedades científicas ou as universidades de alcançarem as demais exigências, num contexto de financiamento público restrito.

\section{Reflexões necessárias: indicativos das razões e estratégias de apropriação do bem comum}

Para Goulart e Carvalho (2008, p. 844), o acesso aberto surgiu como "uma proposta da comunidade científica mundial em torno da ideia de produzir, divulgar e controlar eletronicamente as publicações científicas lançando mão de softwares livres e redes de pesquisadores e/ou instituições com o intuito de dispor pública e livremente sua produção intelectual". Segundo as autoras, desde a Declaração de Budapeste, que em 2001 deu partida ao Movimento de Livre Acesso a Publicações Científicas, um conjunto de cientistas e pesquisadores, profissionais bibliotecários e especialistas em sistemas de informação se dedicou a realizar, solidariamente, um serviço público de grande relevância.
Nos últimos anos essa proposta e esse serviço vem sendo incorporados como novo espaço para investimentos de capital privado. Em vez de cobrar pelo acesso, os editores agora cobram pela publicação, ancorados em uma lógica produtivista da atividade científico-acadêmica. Fetichizada, a publicação guarda um evidente caráter mercantil, exposta a esquemas corrompidos e corrompedores, como se pode acompanhar recentemente com a polêmica dos periódicos predatórios, em vários posts na Internet, como os divulgados no blog do jornalista Maurício Tuffani, especializado em ciência, educação e meio ambiente (TUFFANI, 2015).

Puello-Socarrás (2011, p. 19), lembra que Thorstein Veblen, no início do século passado, percebeu que a nascente ingerência privada nos planos de educação superior nos Estados Unidos conduziria a subordinação da universidade aos interesses dos grandes negócios empresarias, antecipando o fim da esperança de que o avanço dos saberes e das técnicas emancipariam a humanidade. O trabalho de Veblen foi publicado sob o título "The Higher Learning: a memorandum on the conduct of universities by business". Mas, como ressalta PuelloSocarrás (2011, p. 19, tradução nossa), o sub-título originalmente proposto por Veblen era "um ensaio sobre a depravação total". Da profecia vebleniana, passando pelos estudos de Slaugther e Leslie (1997) sobre o capitalismo acadêmico, Puello-Socarrás (2011) nos conduz à orientação predominante neste novo século: o novo neoliberalismo acadêmico. Em outros trabalhos (PUELLO-SOCARRÁS, 2008, 2013) o autor desenvolveu a tese segundo a qual o neoliberalismo, tal como amplamente disseminado nos anos 80 e 90 não se extinguiu, como propõem "ciertas voces hilarantes" (PUELLO-SOCARRÁS, 2011, p. 20). Para ele, persiste um neoliberalismo de novo cunho que, sem modificar o núcleo duro das estratégias de acumulação, se atualiza mediante algumas políticas, como maior presença estatal, mediada por discursos e categorias como empreendedorismo, esfera público-estatal, parcerias público-privadas, etc. Com adaptações seletivas, o neoliberalismo reformula seu programa em torno de políticas econômicas mas não seu projeto político e a correspondente estratégia de acumulação.

Retomando o olhar sobre o projeto SciELO, percebese que o fruto de anos de trabalho, iniciativas e experiências de produção e disseminação de conhecimento construído de forma cooperativa, financiada com recursos públicos, pode se transformar em novo espaço de acumulação capitalista. Isto é, 
bases de dados, como a constituída por SciELO são incorporadas a negócios privados. Neste caso específico, tem peso o fato de que a FAPESP, agência vinculada ao governo paulista, financia $90 \%$ das operações do SciELO; os 10\% restantes advém de recursos do Ministério da Ciência, Tecnologia e Inovação que, desde 2002, apoia o Projeto. Em evento público ocorrido em outubro de 2013, Carlos Henrique de Brito Cruz, diretor científico da FAPESP, enfatizou a necessidade de que o Projeto direcione esforços para sua sustentabilidade financeira bem como para o avanço no processo de internacionalização.

Inspirando-se em David Harvey, Puello-Socarrás (2011, p. 22, grifo do autor, tradução nossa) afirma que, no contexto do novo neoliberalismo acadêmico, se estabelece o gerencialismo que, ao invés de uma privatização pura e simples, busca agenciar a posse de bens e serviços públicos, à moda mesmo da incorporação de um $\square$ espírito $\square$ a um "corpo" que, não passando diretamente à posse daquele "corpo", assume sua personalidade. Assim, mantendo-se como um "corpo" público, fica impregnado do $\square$ espírito $\square$ empresarial, pronto a reproduzir a lógica de mercado.

Com efeito, Harvey (2010, p. 118), explorando as formulações de Rosa Luxemburgo sobre a teoria da sobreacumulação, aprofunda a reflexão da dialética 'interior-exterior' do capitalismo, isto é, “a ideia de que o capitalismo tem de dispor perpetuamente de algo 'fora de si mesmo' para estabilizar-se [...]. Ou seja, requer permanentemente "a transformação em mercadoria de formas culturais, históricas e da criatividade intelectual" $[\ldots] ;[. .$.$] a privatização de bens$ públicos e o apoio do aparato do Estado para manter contínua e persistentemente práticas predatórias de acumulação primitiva. (HARVEY, 2010, p. 123). Este processo Harvey (2010, p. 115 e seguintes) qualifica como "acumulação por espoliação".

Desvalorização de ativos, pressões institucionais e interesses vinculados às expectativas desenvolvimentistas do Estado costumam preceder o avanço do capital privado sobre essas outras práticas ou bens. Apenas para ilustrar, lembremos que a relevância da produção científica brasileira foi fortemente questionada, especialmente desde os anos 1990, em razão de seu baixo índice de internacionalização, ou seja, seu baixo índice de citação em mecanismos como os produzidos pelo ISI. Em 2010, dados divulgados pela Thomson Reuters mostravam que, em 1990, a produção científica brasileira alcançava $0,6 \%$ da produção mundial. Importante notar que produção mundial aqui é aquela que circula nos periódicos analisados pela empresa. Transformado e aceito como um referente universal, o esforço para melhorar a posição brasileira nesse ranking mobiliza agências estatais, desde as voltadas para o financiamento até aquelas responsáveis pelo controle e avaliação da produção científica e tecnológica brasileira que ocorre, quase em sua totalidade, no âmbito de programas de pós-graduação de universidades públicas.

Em 2008, a produção científica brasileira chegou a 2,6\%, segundo colocado entre os BRICs (PRODUÇÃO CIENTÍFICA... 2010). Bastante festejado pelas agências estatais de fomento à pesquisa, o índice estimulou discursos e práticas de aprofundamento da chamada internacionalização da ciência brasileira, cuja ênfase se pode verificar, por exemplo, pelo crescente incentivo do governo brasileiro nesta direção, como era o caso do Programa Ciência sem Fronteiras e outros. Em 2013, a Agência FAPESP anunciava que o número de artigos em inglês publicados em SciELO superava o total de artigos disponibilizados em português. E confirmava que essa tendência "se soma a uma série de esforços para aumentar a visibilidade e o impacto internacional dos artigos publicados em periódicos que integram as coleções indexadas na Rede SciELO, que ainda é baixo em comparação com as dos países desenvolvidos" (ALISSON, 2013). Incorporar SciELO Citation Index ao portfólio da Thomson Reuters é, claramente, parte desses esforços.

Não obstante, esse processo também produz antagonismos. É crescente o número de pesquisadores e sociedades científicas que tem se manifestado acerca dos desdobramentos dos caminhos propostos. Para ilustrar, registramos a criação do Fórum de Editores de Saúde Coletiva, ligado à Associação Brasileira de Saúde Coletiva (ABRASCO). Reunindo muitos dos protagonistas na criação do SciELO, os editores de revistas brasileiras de Saúde Coletiva manifestaram publicamentesuas preocupaçõescom"modificaçõesno panorama da editoração científica nacional, sinalizada por dois importantes atores, a CAPES e a SciELO" (ABRASCO, 2014). Reconhecendo a importância e o compromisso de "aprimorar cada vez mais a qualidade e a visibilidade, nacional e internacional" das revistas que editam, assim como o papel central do SciELO nesta tarefa, os editores alertam para a necessidade de uma "reflexão densa" sobre os conceitos de qualidade e internacionalização. Para eles, a qualidade não pode ser avaliada somente por indicadores bibliométricos e 
tampouco a internacionalização pode ser "entendida apenas como a publicação em inglês de artigos de autores residentes no exterior, nem pode, ou deve, ser exigida uniformemente de todos os periódicos da nossa área".

Adicionalmente, Miguel (2015) chama a atenção para as consequências que os novos critérios para inclusão e permanência em SciELO podem acarretar para os periódicos nacionais. Dentre suas preocupações, salientamos a ingerência sobre decisões editoriais e o aumento de custos de produção das revistas pela obrigatoriedade de formatos que demandam a contratação de profissionais especializados. Miguel (2015) questiona ainda a exigência de cotas de artigos em inglês, tanto pela barreira de acesso que incidirá sobre parcela significativa de estudantes brasileiros quanto pela baixa atratividade dos periódicos nacionais para pesquisadores anglófonos de ponta, o que resultará em que se aproveite "a raspa do tacho da produção anglófona". Pergunta ele: "por que o Brasil deveria financiar revistas para publicar sobretudo textos de autores da América do Norte e da Europa, para serem lidos por um público anglófono da América do Norte e da Europa?

Cabe deixar claro que não tomamos o financiamento estatal como garantia para assegurar a ausência de apropriação privada de bens ou serviços produzidos de modo coletivo e compartilhado. Em outras palavras, não estamos confundindo bem público com bem comum pois, como afirma Harvey (2010, p. 121),

o Estado, com seu monopólio da violência e suas definições da legalidade, tem papel crucial no apoio e na promoção desses processos [de acumulação], havendo [...] consideráveis provas de que a transição para o desenvolvimento capitalista dependeu e continua a depender de maneira vital do agir do Estado.

É também necessário lembrar que desvelar os mecanismos da acumulação por espoliação "ajuda a entender a forma capitalista de imperialismo" (HARVEY,2010,p. 118) nos dias atuais. Assim, a singela narrativa apresentada sobre o projeto SciELO pode contribuir para estimular reflexões sobre este tema. O tema do imperialismo atravessa, subliminarmente, a discussão sobre a produção acadêmico-científica nos países periféricos. Como afirmava Petras (2000), "sob o imperialismo contemporâneo, os interesses políticos são projetados através de assuntos nãoimperiais". Muitas vezes, por assuntos avançados ou pretensamente autodeterminados, como a internacionalização - obsessão atual das agências estatais de fomento e de segmentos da comunidade científica brasileira. Para Ouriques (2011, p. 103) [...] "orientado pelo mito meritocrático" [o pesquisador brasileiro] "é compelido a publicar 'lá fora', em inglês, como se tal procedimento fosse efetivamente o grau máximo da qualificação intelectual”.

Essa condição parece se manifestar nas transformações empreendidas no SciELO quando, em busca da profissionalização, internacionalização e sustentabilidade financeira, se posiciona no "sistema mundial de produção de conhecimento" (OURIQUES, 2011, p. 102) como um intermediário que organiza, mediado por critérios produtivistas, uma linha de produção a serviço da acumulação do capital. Expropriado por grandes grupos privados, o conhecimento acadêmico-científico produzido nesta região do mundo passa, então, a responder a condições de produção, circulação e consumo ditadas externamente. Reproduz, no campo acadêmicocientífico, a dependência estrutural das periferias do mundo (MARINI, 2005), adicionando um anel na espiral da relação de dependência em relação a centros definidores dos rumos do conhecimento.

Não ignoramos que, como é próprio ao sistema do capital, a contradição fundante é a dialética capital trabalho, com derivações para a esfera específica da produção do conhecimento. Neste texto, iniciamos por explorar o fenômeno aparente - a publicação. Fetichizada, dissimula os processos que a engendram; analisar profunda e radicalmente esses processos não só desvenda o fetiche, mas oferece elementos para a ação transformadora.

\section{REFERÊNCIAS}

ABRASCO. Fórum de Editores de Saúde Coletiva: carta de São Paulo. São Paulo, 18 nov. 2014. Disponível em: http://www.abrasco.org.br/site/wp-content/ uploads/2014/11/Nota-Forum-de-Editoresde-Saude-Coletiva-_2014-11-18.pdf. Acesso em: 05.01.2015. 
ACHARYA, A. e outros. Rise of the rest: the growing impact of non-elite journals. Eprint arXiv:1410.2217. Oct., 2016. Disponível em http:// arxiv.org/abs/1410.2217. Acesso em 25 mai. 2016.

ALLISON, E. Número de artigos em inglês supera os publicados em português na SciELO Brasil. Agência FAPESP, 25 out. 2013. Disponível em: http://agencia.fapesp.br/18109. Acesso em: 11.11. 2013.

ALPSP. The facts about open access. [S.1.], 2005. Disponível em: http:/ /www.alpsp.org. Acesso em: 15.07.2007.

ARCHAMBAUT, E.; LARIVIÈRE, V. History of de journal impact factor: contingencies and consequences. Scientometrics, v. 79, n.3, p. 635-649, 2009.

BENSAID, D. Potências do comunismo. Carta Maior, 13 jan. 2010. Disponível em: http://www. cartamaior.com.br/?/Editoria/Internacional/ Daniel-Bensaid-a-atualidade-de-um-comunismoradical\%0D\%0A/6/15236. Acesso em: 0202.2014.

BIOMED CENTRAL. Open Access journals get impressive impact factors. [S.l.], 2005. Disponível em: http://www.biomedcentral.com/info/about/prreleases?pr $=20050623$. Acesso em 21.07.2007.

BOHANNON, J. Who's Afraid of Peer Review? Science, v. 342, n. 6154, p. 60-65, 4 Oct. 2013.

Disponível em: doi: 10.1126/science.342.6154.60. Acesso em 10.10.2013.

BRIQUET DE LEMOS. Periódicos eletrônicos: problema ou solução? [S.1.], 2005. Disponível em: http://www.briquetdelemos.com.br/artigo07. Acesso em 31.01.2014.

DECLARAÇÃO recomenda eliminar o uso do fator de impacto na avaliação de pesquisa. SciELO em Perspectiva, 16 jul. 2013. Disponível em: http://blog. scielo.org/blog/2013/07/16. Acesso em 10.11.2013.

DINIZ, E. Acesso aberto: um tema a ser mais bem explorado. ERA-revista de administração de empresas,v. 55, n. 5, set.-out., 2015. Disponível em: http://www. scielo.br/pdf/rae/v55n5/0034-7590-rae-55-05-0479. pdf. Acesso em: 01.11.2015.

GARFIELD, E. Citation index for science. Science, n. 122, p. 108-111, 1955. Republicado em Essays of an Information Scientist, v. 6, p. 468-471, 1983.
Disponível em http://garfield.library.upenn.edu/ essays/v6p468y1983.pdf. Acesso em: 01.03.2016.

GOULART, S. Acesso livre a publicações científicas: perspectivas e desafios para os pesquisadores brasileiros em Administração. Gestão.Org, v. 4, n. 3, 2006. Disponível em: http://www.revista.ufpe.br/ gestaoorg/index.php/gestao/issue/view/46. Acesso em 20.01.2014.

GOULART, S.; CARVALHO, C. A. O caráter da internacionalização da produção científica e sua acessibilidade restrita. Revista de Administração Contemporânea, v. 12, n. 3, p. 835-853, 2008.

Disponível em: http://www.scielo.br/pdf/rac/ v12n3/11.pdf. Acesso em 10.04.2015.

GUIMARÃES, J. A. Brazilian higher education: recent changes (2004 - 2013): perspectives and challenges for institutions to reach the level of a World-Class University. In: SYMPOSIUM ABC - FAPESP: excellence in higher education, São Paulo, 2014. Disponível em: http://www.fapesp.br/ eventos/2014/01/Excellence/Jorge_Guimaraes.pdf. Acesso em: 28.01.2014.

HARVEY, D. O novo imperialismo. 4. ed. São Paulo: Loyola, 2010.

HERSCHMAN, A. The primary journal: past, present and future. Journal of Chemical Documentation, v. 10, n. 1, p. 37-42, Feb, 1970.

LARIVIÈRE, V.; HAUSTEIN, S.; MONGEON, P. The Oligopoly of academic publishers in the digital era. PLoS ONE, v. 10, n. 6, p. 1-15. e0127502. doi:10.1371/journal.pone.0127502.

LEFEBVRE, H. Critique of everyday life. London: Verso, 2014. v. 1.

MACHADO, A. M. N.; BIANCHETTTI, L. (Des) fetichização do produtivismo acadêmico: desafios para o trabalhador-pesquisador. RAE-revista de administração de empresas, v. 51, n. 3, p. 244-254, 2011. Disponível em:http://www.scielo.br/pdf/rae/ v51n3/v51n3a05.pdf. Acesso em: 10.07.2011.

MARINI, R. M. Dialética da dependência: 1973. In: TRASPADINI, R.; STEDILE, J. P. (Org). Rui Mauro Marini: vida e obra. São Paulo: Expressão Popular, 2005. p. $137-180$.

MARX, K. Capital. London: Penguin Classics, 1990. v. 1. 
MENDONÇA, A. Gestão avançada da avaliação de manuscritos dominou o I Curso de Atualização SciELO-ScholarOne. SciELO em Perspectiva. Disponível em http://blog.scielo.org/ blog/2015/08/17/gestao-avancada-da-avaliacaode-manuscritos-dominou-o-i-curso-de-atualizacaoscielo-scholarone/. Acesso em 10. 11.2015.

MERTON, R. K. Priorities in scientific discovery (1957). In: _ . The Sociology of science: theoretical and empirical investigations. Chicago: University of Chicago, 1973. Cap. 14, p. 286-324.

MIGUEL, L. F. Qual é a do SciELO? UOL: painel acadêmico, 06 out. 2015. Disponível em: http:/ / painelacademico.uol.com.br/painel-academico/5263qual-e-a-do-scielo. Acesso em 10.10.2015.

MUELLER, S. P. M. A comunicação científica e o movimento de acesso livre ao conhecimento. Ciência da Informação, v. 35, n. 2, 2006. Disponível em: http:/ / www.scielo.br/pdf/ci/v35n2/04v35n2.pdf. Acesso em: 11.11.2006.

OURIQUES, N. Ciência e pós-graduação na universidade brasileira. In: RAMPINELLI, W. J.; OURIQUES, N. Crítica à raz̃ão acadêmica: reflexão sobre a universidade contemporânea. 2. ed. rev. Florianópolis: Insular, 2011. p. 73-107.

PACKER, A. L. e outros. SciELO: uma metodologia para publicação eletrônica. Ciência da Informação [online], v. 27, n. 2, 1998. Disponível em: http://www. scielo.br/scielo.php? script $=$ sci_arttext\&pid $=$ S0100$19651998000200002 \& \operatorname{lng}=$ en\&nrm $=$ iso. Acesso em: 27.04.2005.

PACKER, A. L. Entrevista com Abel L. Packer. Acesso Aberto.Boletim do Portal de Revistas Eletrônicas da PUC-SP, n.2, 2013. Disponível em: http:// revistas.pucsp.br/index.php/acessoaberto/article/ view/13650/10151. Acesso em 10.11.2013.

PETRAS, J. Cultural imperialism in the late $20^{\text {th }}$ century. Rebelión, 2000. Disponível em: http://www. rebelion.org/hemeroteca/petras/english/cultural_ imperialism.htm. Acesso em: 06.06.2006.

PRODUÇÃO Científica do Brasil ultrapassa a da Rússia, indica levantamento. UOL. São Paulo, 27 jan. 2010. Disponível em: http://educacao.uol.com.br/ ultnot/bbc/2010/01/27/producao-cientifica-dobrasil-ultrapassa-a-da-russia-indica-levantamento. jhtm. Acesso em: 27.01.2010.
PUELLO-SOCARRÁS, J. F. Nueva gramática del neo-liberalismo: itinerários teóricos, trayectorias intelectuales, claves ideológicas. Bogotá: Universidad Nacional de Colombia, 2008.

PUELLO-SOCARRÁS, J. F. Un ensayo sobre la depravación total: nuevo neoliberalismo acadêmico y capitalismo 'por posesión'. Revista Izquierda, n. 14, 2011. Disponível em: http://www.espaciocritico. com/node/97. Acesso em 25.04.2015.

PUELLO-SOCARRÁS, J. F. Ocho tesis sobre El neoliberalismo (1973-2013). In: RAMIREZ, H. (Org). O neoliberalismo sul-americano em clave transnacional: enraizamento, apogeu e crise. São Leopoldo: Oikos, 2013. p. 13-57.

QUANTO custa publicar em acesso aberto? SciELO em Perspectiva, 18 set. 2013. Disponível em: http:// blog.scielo.org/blog/2013/09/18/quanto-custapublicar-em-acesso-aberto/. Acesso em: 22.11.2013.

QUÉAU, P. A quem pertence o conhecimento? Le Monde Diplomatique Brasil, 01 jan. 2000. Disponível em: https://www.diplomatique.org.br/acervo. php?id=167. Acesso em: 10.02.2014.

SCIELO. Critérios, politica e procedimentos para a admissão e a permanência de periódicos científicos na Coleção SciELO Brasil. São Paulo, set. 2014. Disponível em: http:// www.scielo.br/avaliacao/20141003NovosCriterios_ SciELO_Brasil.pdf. Acesso em 30.10.2015.

SLAUGHTER, S.; LESLIE, L. Academic capitalism: politics, policies and the entrepreneurial university. Baltimore: Johns Hopkins, 1997.

SOLOMON, D. Digital distribution of academic journals and its impact on scholarly communication: looking back after 20 years. The Journal of Academic Librarianship, v. 39, n. 1, p. 23-28 Jan. 2013. Disponível em http://dx.doi.org/10.1016/j. acalib.2012.10.001. Acesso em 25 mai. 2016.

Disponível em: http://wokinfo.com/products_ tools/multidisciplinary/scielo/. Acesso em: 10.11.2013.

THOMSON REUTERS. The citation conection: history. Web of Knowledge, 2013. Disponível em: http://wokinfo.com/citationconnection/. Acesso em: 12.02.2014.

TUFFANI, M. Ciência, cultura, ensino superior e ambiente. UOL, out. 2015. Disponível em: http:// 
mauriciotuffani.blogfolha.uol.com.br/perfil/, acesso em 01.11.2015.

UNITED KINGDOM. House of Commons.

Science and technology committee. Scientific

Publication: free for all?, London, Jul. 2004. (HC-

399-I). Disponível em: http:/ / www.publications. parliament.uk/pa/cm200304/cmselect/

cmsctech/399/399.pdf. Acesso em 12.01.2014.

WHAT'S wrong with Science. And Nature. and Cell: a Nobel prize-winner attacks elite journals. The Economist, 14 dec. 2013. Disponível em:

http://www.economist.com/news/science-andtechnology/21591549-and-nature-and-cell-nobelprize-winner-attacks-elite-journals-whats-wrong. Acesso em: 10.01.2014. 